\title{
Greater Number of Group Identifications is Associated with Healthier
}

\section{Behaviour in Adolescents}

\author{
Kirsty Miller*, Juliet R. H. Wakefield, \& Fabio Sani \\ School of Psychology, University of Dundee, Dundee, Scotland
}

Word count (exc. Figures/tables): 4,979

\section{Acknowledgements}

This research was conducted as part of the first author's $\mathrm{PhD}$., which was funded by the

School of Psychology, University of Dundee, Scotland. We would like to thank the Staff, Carers and Pupils of the schools involved for their assistance with the project. 


\begin{abstract}
We investigated the relationship between group identification (with the family, school, and friendship groups) and adolescent health behaviour (smoking, binge drinking, and cannabis use). 1,111 students from 4 Scottish secondary (high) schools completed a questionnaire which included measures of group identification, group contact, health behaviours, and demographic variables. We found that identification with the family and school groups predicted reduced odds of substance use, whereas identification with the friend group predicted increased odds of substance use. Furthermore, the greater the number of social groups with which the participant strongly identified, the lower the odds that he/she participated in negative health behaviours. In contrast, merely having contact (rather than identifying strongly) with these groups increased the odds of participation in these behaviours. We suggest that group identification influences behaviour to the extent that it encourages adherence to group norms.
\end{abstract}




\section{Greater Number Of Strong Social Group Identifications Is Associated With Healthier \\ Behaviour In Adolescents}

Membership in one or more social groups (e.g., family, tribe, community, sport team) is a core aspect of our existence (Tomasello, 2014). Clearly, group membership provides one with an opportunity to engage in communal activities and intense interaction. However, group membership may also involve a sense of attachment and belonging to the group, coupled with feelings of commonality with other fellow group members. This subjective dimension of group life has been conceptualised by researchers as group identification (e.g., Sani, Madhok, Norbury, Dugard, \& Wakefield, 2015; Cruwys et al., 2014).

\section{Group identification and health}

Social psychologists adopting a social identity approach to group processes (Tajfel \& Turner, 1986) have shown the important effects that group identification can have on cognitions and behaviour. For instance, we are more likely to like, be influenced by, give help to, and accept help from those whom we perceive to belong to a group with which we identify (e.g., Haslam, 2004; Turner, Hogg, Oakes, Reicher \& Wetherell, 1987). Furthermore, researchers have established a strong positive link between group identification and well-being (e.g. Haslam, Jetten, Postmes, \& Haslam, 2009).

For instance, Wakefield, Bickley, and Sani (2013) recruited a sample of people with multiple sclerosis who were participating in support groups, and found a negative association between identification with the support group and symptoms of depression and anxiety. This is consistent with recent work by Cruwys and colleagues (2013) who found that greater number of group identifications is linked to better psychological outcomes. Furthermore, Wegge, van Dick, Fisher, Wecking, and Moltzen (2006) recruited people working in call centres, and found an association between higher levels of organisational identification and fewer health complaints. Greater 
identification with fellow Hindus even predicted increased self-rated health amongst pilgrims after attending a large, noisy, and unsanitary religious festival in rural India (Khan et al., 2014).

Although this research focuses predominantly on adult samples, there is also evidence to support the existence of a positive relationship between group identification and well-being in children and adolescents. For instance, Bizumic, Reynolds, Turner, Bromhead, and Subasic (2009) recruited a sample of high school students, and found that higher identification with the school predicted lower anxiety, depression, and loss of emotional control, as well as higher self-esteem and positive affect. Additionally, Miller, Wakefield, and Sani (2015) found that mental well-being was positively predicted by family, school and friend identification in high school students, and that the more groups students identified with, the mentally healthier these students were.

\section{Group Identification and Health Behaviour}

Group identification also has a relationship with health practices to the extent that it influences participation in health-related behaviours (e.g., drinking, smoking, eating, and exercise). For instance, in a longitudinal study involving a large sample of young Australian adults, Schofield, Pattison, Hill, and Borland (2001) showed a positive association between smoking and favourable smoking norms in one's peer group. A study involving UK university students, for whom heavy drinking is normative, revealed a similar positive association between identification with the group 'UK university students' and drinking intentions (Livingstone, Young, \& Manstead, 2011). Additionally, the link between group identification and healthier group norms such as healthy eating (Åstrøm \& Rise, 2001), exercise, and sun-protective behaviour (Rivis \& Sheeran, 2003; Terry \& Hogg, 1996) have also been observed.

Taking these insights a step further, the importance of social identification has been illustrated in relation to clinical populations, where identification with certain types of groups is positively associated with eating disorders or substance use (e.g. Cruwys, Haslam, Fox, \& 
McMahon, 2015; Dingle, Cruwys, \& Frings, 2015). This is because defining oneself in terms of a specific identity (such as a substance using identity) may encourage behaviour in accordance with this identity (e.g. Schofield et al., 2001). This means however, that in the same way that identity processes can encourage risky or unhealthy behaviour, they can also be used to treat it. Indeed, in line with the Social Identity Model of Cessation Maintenance (Frings \& Albery, 2015), and the more recent Social Identity Model of Recovery (Best et al., 2016), work with those suffering from substance use problems has shown that the introduction, development, and maintenance of 'recovery' or 'non-substance using' identities can enhance treatment outcomes amongst those with substance use disorder (e.g. Beckwith, Best, Dingle, Perryman, \& Lubman, 2015; Dingle et al., 2015; Dingle, Stark, Cruwys, \& Best, 2014).

From the work described above, it is evident that group identification can encourage either positive or negative behaviours depending on the groups in question. However, to date, there has been little work examining the impact of multiple group identifications on behaviour. This is important because we tend to identify with multiple groups simultaneously, and can therefore be influenced by a variety of norms. Indeed, recent work with adults suggests that identifying with multiple groups predicts healthier behaviour (Sani, et al., 2015). Sani and colleagues proposed three pathways which may explain this relationship: i) increased willingness to comply with group norms; ii) the sense of purpose and meaning provided by group identification (which increases motivation to look after oneself), and; iii) the sense of duty and obligation to others provided by identifying with groups. The authors argued that multiple group identifications protect against negative health behaviours to the extent that the positive psychological aspects of identifying with groups (i.e. the latter two pathways) will compensate for any unhealthy behavioural norms.

This theory is consistent with work conducted by Verkooijen, Nielsen, and de Vries (2007) which investigated the relationship between health behaviours and identification with a variety of adolescent sub-groups. They found that identifying with multiple groups possessing similar norms 
increased normative behaviour, whereas identifying with multiple groups possessing competing norms decreased normative behaviour. This work therefore supports the theory that identification with groups possessing healthy norms can reduce the negative effects of identifying with groups possessing unhealthy norms.

\section{The Present Study}

Extending work by Sani and colleagues (2015) and Verkooijen et al. (2007), the current study further investigates the impact of multiple group identifications on health behaviours in young people. While it would have been insightful to invite students to choose the groups with which they identified (as per Sani et al.'s 2015 study), it was considered important to keep the instructions as simple, and the questionnaire as brief, as possible. Consequently, we decided to focus on three key groups for adolescents: the family, school, and friends (Viner et al., 2012).

In relation to the norms of each of the groups, it is likely that the family and the school will be more likely to encourage healthy behaviours than friends will. Consistent with previous work suggesting that group identification promotes norm adherence, we hypothesised that family and school identification will predict healthier behaviour than identification with the peer group. In addition, we hypothesised that multiple group identifications will predict healthier behaviour, thus compensating for any individual group norms that encourage unhealthy behaviour.

\section{Method}

\section{Participants and Procedure}

The study is based on Wave 1 of a 2-wave longitudinal research project that involved 1111 students (553 males, 553 females, 5 unspecified; $M_{\text {age }}=15.07$ years, $S D=0.97$, range: $13-17$ years) attending four Scottish public secondary schools. Schools were chosen based on their willingness and ability to participate fully in both waves. Parental and student permission was obtained, and 
students were reminded of their right to withdraw before commencement of the testing sessions. Only one individual chose not to participate. Participants completed a questionnaire in class time under exam conditions, either in assembly or in class. The questionnaire was administered either by the researcher or by class teachers. In cases where the researcher was not present, the teachers administering the questionnaire were fully briefed on ethical and procedural considerations. Participants completed the questionnaire anonymously (although codes were used to allow the linking of Wave 1 and Wave 2 data).

\section{Questionnaire Measures}

Group identification. We measured participants' identification with three distinct social groups: the family, the school, and a friendship group. Concerning 'family', participants were instructed to consider "your immediate family or the people you live with most of the time, for example, your parents, carers, step-parents, or other family members who live with you in your house". Concerning 'school', participants were asked to think about it in terms of "an institution with its history, values and beliefs". Finally, concerning 'friends', participants were asked to think about "the group of friends that you spend most time with or your 'best' friends".

Identification with each group was assessed with the widely used four-item scale devised by Doosje, Ellemers, and Spears (1995). All items (e.g., "I feel strong ties with members of [group]") were rated using a 1 ('I strongly disagree') to 7 ('I strongly agree') scale, and participants' responses were averaged to create measures of family, school, and friendship group identification (Cronbach's $\alpha \mathrm{s}=.92, .89$, and .91 respectively).

Three binary variables for each group identification measure (i.e., family, school, and friendship group) were then created by calculating each participant's average identification score for each of the three groups. If a participant's average score was 5 or less for a particular group, they received ' 0 ' for that binary variable (indicating they did not identify strongly with that particular 
group), while if their average score was 6 or 7 they received ' 1 ' for that binary variable (indicating they identified strongly with that particular group). We then summed the three binary variables to create a variable indicating each participant's number of group identifications. This ranged from 0 (indicating the participant did not identify with any of the three groups) to 3 (indicating the participant identified with all three groups).

Group contact. For each of the three groups considered (family, school, and friends), we asked two questions assessing the extent of contact participants had with other ingroup members: "How many members of your family/school/group of friends do you talk to (face to face) on a normal day? Please give a number", and "How many members of your family/school/group of friends do you talk to on the phone, by text or online (including email, Facebook, chat-rooms, discussion boards, etc.) on a normal day? Please give a number”. This measure was adapted from an instrument devised by Sani, Herrera, Wakefield, Boroch, \& Gulyas (2012).

For each of the three groups, we transformed each participant's responses to the two contact questions into $Z$-scores, and summed these two $Z$-scores into an overall measure of contact. The group was considered to be either not contact-intensive for the participant, if they scored below 0 (less than average contact), or contact-intensive for the participants, if they scored 0 or more (average/higher than average contact). We summed these three binary variables to create a measure of each participant's number of contact-intensive groups. This ranged from 0 (indicating the participant did not have any contact-intensive group) to 3 (indicating that all three groups were contact-intensive for the participant).

Health behaviours. Self-reported health behaviours were measured using items included in the Youth Risk Behaviour Survey (Brener et al., 2004). The items concerned tobacco smoking (referred to henceforth as 'smoking'), binge drinking (defined as drinking more than 5 alcoholic drinks in one session) and cannabis use. Specifically, participants were asked: (1) 'during the past 30 days, on 
how many days did you smoke cigarettes?', (2) 'during the past 30 days, on how many days did you have 5 or more drinks of alcohol in a row, that is, within a couple of hours?', and (3) 'during the past 30 days, how many times did you use cannabis?'.

In order to be consistent with Sani and colleagues (2015) work, we created three binary variables (one for each health behaviour), indicating whether or not the participant had engaged in that behaviour at least once during the past 30 days. Participants indicating that they had not engaged in the behaviour (e.g., they had not smoked tobacco) received a 0 for that behaviour's binary variable. Participants indicating that they had engaged in the behaviour (e.g., they had smoked tobacco once, or used cannabis five times) received a 1 for that behaviour's binary variable.

Demographic variables. Participants indicated their gender and age.

\section{Results}

\section{Cross Tabular Analyses}

Number of strong group identifications. We began by investigating health behaviour frequencies (smoking, binge drinking, and cannabis use) as a function of number of strong group identifications. Table 1 reports these frequencies, together with the chi-square value (and statistical significance) for each of the three health behaviours. This analysis shows that the proportion of participants adopting a given behaviour slightly increases among those with one strong group identification, compared to those without any strong identifications. However, strong identification with two and three groups is associated with an incremental reduction in the proportion of participants adopting a given behaviour. For instance, concerning smoking, $24.10 \%$ of respondents without any strong group identification smoked at least once, compared to $26.40 \%, 15.70 \%$ and $8.80 \%$ for respondents with one, two, and three strong group identifications respectively. The associations between number of strong group identifications and smoking, $\chi^{2}(3, N=1089)=36.97, p$ 
$<.001$, binge drinking, $\chi^{2}(3, N=1089)=25.76, p<.001$, and cannabis use, $\chi^{2}(3, N=1085)=41.95$, $p<.001$ were all significant.

(TABLE 1)

Number of contact-intensive groups. We then looked at health behaviour frequencies as a function of the number of contact-intensive groups. The chi-square value (and statistical significance) for each health behaviour are reported in Table 2. We found that as the number of contact-intensive groups increased, so did the proportion of participants engaging in smoking, binge drinking, and cannabis use. However, in this case there was only a statistically significant result for binge drinking, $\chi^{2}(3, N=940)=10.35, p=.02$, while the results for smoking and cannabis use were non-significant $(p s>.48)$.

(TABLE 2)

Gender. Health behaviour frequencies were also measured as a function of gender. The chisquare value (and statistical significance) for each health behaviour are reported in Table 3. Males were less likely to smoke, $\chi^{2}(1, N=1093)=11.54, p<.001$, and binge drink, $\chi^{2}(1, N=1090)=4.50$, $p=.03$ than females. There was not a statistically significant difference between genders for cannabis use $(p=.11)$.

(TABLE 3)

\section{Point-biserial Correlations}

To investigate the association between age and the different types of health behaviours, we conducted three point-biserial correlations. We found age to be positively associated with smoking $\left(r_{p b}=.08, p=.01\right)$, binge drinking $\left(r_{p b}=.27, p<.001\right)$, and cannabis use $\left(r_{p b}=.06, p=.04\right)$.

\section{Logistic Regression Analyses for Multiple Group Identifications}


We then performed three direct binary logistic regressions in order to investigate the effects of number of strong group identifications, high group contact, gender, and age - on smoking, binge drinking, and cannabis use respectively.

Assumptions. We first checked whether the data met the assumptions required for logistic regression. Tolerance values ranged from .30 to .98 , while the highest Variance Inflation Factor value was 3.37, clearly indicating a lack of multicollinearity. Finally, we investigated outliers. In none of the regressions did the number of cases with a studentized residual above 2.00 reach a value that would cause concern. We thus proceeded with the analyses.

\section{Analyses.}

Smoking. The first regression (Table 4) examined the impact of the predictors on the smoking variable. The full model was significant, $\chi^{2}(4)=43.77, p<.001$. All predictors made a unique statistically significant contribution to the model. Gender was the strongest predictor, with females having greater odds of smoking than males, $\mathrm{OR}=0.52$. Number of strong group identifications was also a strong predictor, with each additional strong group identification predicting reduced odds of smoking, $\mathrm{OR}=0.62$. Finally, the older students were, and the more contact-intensive groups they had, the greater the odds of them smoking, ORs $=1.24$ and 1.31 respectively.

\section{(TABLE 4)}

Binge drinking. The second regression examined the impact of the four predictors on the binge drinking variable (Table 5). The full model was significant, $\chi^{2}(4)=115.77, p<.001$. Again, all predictors made a unique statistically significant contribution to the model. The strongest predictor was gender, with females having greater odds of binge drinking than males, $O R=0.68$. Strong group identifications was also a strong predictor, with each additional strong group identification predicting reduced odds, $\mathrm{OR}=0.72$. Increased age and more contact-intensive groups predicted greater odds of binge drinking, $\mathrm{ORs}=2.03$ and 1.45 respectively. 
(TABLE 5)

Cannabis use. The third regression examined the impact of the four predictors on the cannabis use variable (Table 6). The full model was significant, $\chi^{2}(4)=32.66, p<.001$. Two predictors were found to have statistically significant unique effects on cannabis use: strong group identifications and contact-intensive groups. Strong group identifications was the strongest predictor, with each additional strong group identification predicting reduced odds of cannabis use, $\mathrm{OR}=0.52$. In contrast, more contact-intensive groups predicted greater odds, $\mathrm{OR}=1.43$.

(TABLE 6)

\section{Logistic Regression Analyses For Individual Group Identifications}

We then performed three direct binary logistic regressions to investigate the independent effects of eight predictors (identification with each of the three groups, contact with each of the three groups, gender, and age) on smoking, binge drinking, and cannabis use respectively

\section{Analyses.}

Smoking. The first regression (Table 7) examined the impact of eight predictors (identification and contact with each group, plus gender and age) on the smoking variable. The full model was significant, $\chi^{2}(8)=70.41, p<.001$, indicating an improvement over the independence model (i.e., a model with no predictors in the equation). Both family and school identification predicted reduced odds of smoking, ORs $=0.65$ and 0.74 respectively. In contrast however, friend identification predicted increased odds of smoking, $\mathrm{OR}=1.35$. Group contact did not impact on odds of smoking for any group. Gender was the strongest predictor of smoking, $\mathrm{OR}=0.49$, with females having greater odds of smoking than males. Finally, increasing age also predicted increased odds of smoking, $\mathrm{OR}=1.28$.

(TABLE 7) 
Binge drinking. The second regression examined the impact of the eight predictors on the binge drinking variable (Table 8 ). The full model was significant, $\chi^{2}(8)=152.46, p<.001$. Both family and school identification predicted decreased odds of binge drinking, ORs $=0.69$ and 0.73 respectively, while friend identification predicted increased odds, $\mathrm{OR}=1.63$. While family and friend contact did not have a significant impact, increased school contact predicted increased odds of binge drinking, $\mathrm{OR}=1.43$. Females also had greater odds of binge drinking than males, $\mathrm{OR}=0.67$, and increasing age also predicted increased odds, $\mathrm{OR}=2.1$.

(TABLE 8)

Cannabis use. The third regression examined the impact of the predictors on the cannabis use variable (Table 9). The full model was significant, $\chi^{2}(8)=56.63, p<.001$. Both family and school identification predicted reduced odds of cannabis use, ORs $=0.64$ and 0.63 respectively, whereas friend identification predicted increased odds, $\mathrm{OR}=1.47$. No other predictors were significant.

(TABLE 9)

\section{Discussion}

The results confirm our predictions and support the findings of Sani and colleagues (2015). In an adolescent sample, family and school identification both predicted reduced odds of engaging in unhealthy behaviours (smoking, binge drinking, or using cannabis at least once in 30 days), whereas friend identification predicted increased odds of engaging in these behaviours. Group contact did not have a significant relationship with health behaviours, with the one exception that increased school contact predicted increased odds of binge drinking. Finally, the greater the number of groups with which participants identified strongly, the lower the odds that they would smoke, binge drink, or use cannabis at least once in 30 days.

These findings can be interpreted as supporting previous work which showed that group identification predicts behaviour in accordance with group norms (e.g. Schofield et al., 2001; 
Livingstone et al., 2011; Åstrøm \& Rise, 2001). Since adolescents tend to be more drawn towards risky behaviours (Hogg, Siegel, \& Hohman, 2011), it is unsurprising that identification with the friend group increases the likelihood of participating in unhealthy behaviours, whereas we would expect family and school (in most cases) to encourage healthy behaviours - an expectation that was also supported by the current results.

That contact and identification with each of three groups have different relationships with health behaviours supports the distinction between group identification and group contact suggested by Sani et al. (2012). However, it is noteworthy that school contact predicts increased binge drinking, while family and friend contact does not. It is possible that this could be due to school staff's expectations that young people tend to drink to excess, thus increasing the students' feeling that binge drinking is normative. Indeed, it has been shown that campaigns designed to improve health that highlight the prevalence of a specific unhealthy behaviour can actually lead to increased participation in that very behaviour (e.g. Livingstone, Young, \& Manstead, 2011). However, future research should investigate whether these results are replicated in a different sample.

The finding that more strong group identifications predicted reduced odds of engaging in unhealthy behaviour is also consistent with Sani and colleagues' (2015) work. This could be because more group identifications increase the likelihood of individuals identifying with a group with healthy norms, which will help protect against negative behaviour. Indeed, in the current study, it is only identification with the friend group that predicts unhealthy behaviour, so it is likely that identification with the family and school group protect against the negative norms encouraged by identification with the friend group.

The current work also shows a clearer pattern than Sani et al.'s (2015) regarding the different relationships that number of strong group identifications and number of contact-intensive groups have with health behaviour. Specifically, while Sani et al. (2015) found that number of contact- 
intensive groups was virtually unrelated to health behaviour, the current study shows that larger numbers of contact-intensive groups actually predicted increased odds of smoking, drinking, and cannabis use. While this again points to the importance of psychological connectedness to the group, rather than mere frequency of interaction with other in-group members, it is not entirely clear why group contact increases the likelihood of participation in risky behaviours. It is possible however, that these findings are specific to the sample in question: due to young people having little control over the amount of contact they have with their groups (in particular the amount of time they spend with their family and school), they may feel resentful of the obligation to spend so much time with them - or indeed, of the lack of control they have over their own lives. This in turn may lead to rebellious or destructive behaviour, which may take the form of substance use. In contrast, if these groups are identified with, then the contact would tend to be more enjoyable, and the protective aspects of group identification would apply. Indeed, if young people identify strongly with their family and/or school, as well as conforming to more positive group norms regarding behaviour, they may also be more likely to refrain from participating in risky behaviours in order to avoid causing undue distress to those who care about them.

\section{Limitations and Future Directions}

Our study is not without its limitations, one of which is its cross-sectionality. This means that we must be cautious regarding any speculation about causal links between group identification and health behaviour. Although it is theoretically legitimate to suggest that group identification influences health behaviour, we cannot completely rule out the possibility of reverse causation (an unhealthy lifestyle leading to reduced opportunity to identify with social groups). Longitudinal data provided by the second wave of our study should shed light on this issue.

A further limitation involves the use of questionnaires for collecting information about participants' past behaviors, the reliability of which could be affected by memory lapses or social 
desirability concerns. However, given the number of participants involved in the study, other methods of data collection would be impractical. Moreover, we believe that our policy of anonymity encouraged participants to respond truthfully and thoughtfully.

It is also worth noting that although our results show an overall decrease in risky health behaviours as participants' number of group identifications increases, there is a notable exception for those who only identify strongly with one group. Specifically, we find that such individuals show higher levels of participation in all three risky health behaviours, compared with those who identify strongly with no groups. Consistent with our hypothesis, we suggest that only identifying strongly with a single group may mean that individuals are more likely to be influenced by any negative norms associated with that specific group, without having the protective influence of other groups. In our study, this negativity could originate from identification with the peer group, while additional group identifications with the family and school could offer protection. Indeed, it is noteworthy that Sani et al. (2015) did not observe this pattern with an adult sample: instead, they found that unhealthy behaviour decreased with each group identification, thus suggesting that these adults were not particularly influenced by any potentially negative behavioural norms associated with a single group. This inconsistency would be a potentially fruitful avenue for future research, and may provide insights into the pathways associated with group identification and health-related behaviour in different populations across the life-course.

There should also be a note of caution regarding the generalizability of our results. Although the findings regarding the protective nature of multiple group identifications support those of Sani and colleagues (2015), it is important to note that these results may be partly due to the specific groups under investigation. Since Sani et al. (2015) investigated the extent of identification with the family, local community, and a group of participant's own choice in a non-clinical population, it is likely that the norms of these groups would be generally positive regarding health behaviours (as with the family and school groups in the current study). Indeed, this theory is consistent with the 
point discussed above (that each additional group identification protects against risky behaviour). However, were we to consider groups with more unhealthy norms, the results would likely be very different. This is particularly pertinent, as we have seen, when considering clinical populations such as those suffering from substance use disorders. Here, it is likely that original identities (such as those related with the family, work group, community, etc.) are lost and replaced with those which encourage substance use (e.g. Dingle et al., 2014). Although we have seen that it is possible to encourage dis-identification with such groups, and encourage identification with others (e.g. Best et al., 2016), it would be better to avoid identification with such groups in the first instance. The implications of this are that we need to be careful when advocating group identifications as being protective against risky health behaviours, as the extent of this protective nature will depend on the groups in question.

Finally, while the focus of the current paper has surmised the role of group norms in mediating the relationship between identification and behaviour, future research should measure the relevant group norms in order to investigate their role. Indeed, it would also be useful to investigate the role of a variety of potential mediating factors, including those discussed by Sani and colleagues (2015), such as group identification promoting an obligation to look after oneself.

\section{Implications}

Assuming that group identification does indeed determine health behaviour among adolescents, we suggest that stakeholders should devise strategies in order to encourage adolescents to invest psychologically in groups - specifically groups that have healthy norms. This latter is crucial, as we have seen from work involving those suffering from addictive disorders (e.g. Dingle et al., 2014; Best et al., 2016). Although Sani and colleagues' (2015) previous work suggested that multiple group identifications encourage participation in healthy behaviours, with the implication 
that they can even protect against identification with groups with unhealthy norms, we have to be clear that this process is dependent on the norms of the groups in the question being positive.

It is also important to bear in mind the importance of encouraging identification with the group in question, rather than merely finding ways to encourage intragroup interaction. There will clearly be a degree of overlap between the two concepts, with increased contact possibly increasing identification as group members foster and develop relationships with each other. However, as we have seen, there is no guarantee that simply spending time with fellow group members will increase group identification, as the resultant contact could be characterised by negativity, judgement, or conflict, which, if anything, could reduce identification.

From a longer-term perspective, it is important to remember how crucial it is to encourage adolescents to engage in healthy behaviours as a way to improve their wellbeing into adulthood. For instance, Kelder, Perry, Klepp, and Lytle (1994) found that adolescents who smoke are likely to continue smoking (and to smoke more) as they age, leading the authors to recommend that behavioural change interventions are started in early adolescence, before negative health behaviours become change-resistant. The advantage of initiatives that encourage identification with groups possessing healthy norms is that they could essentially begin from birth, and could also provide children/adolescents with a host of other mental and physical health benefits that have been shown to stem from strong group identifications (e.g., Jetten, Haslam, \& Haslam, 2012).

To conclude, our results highlight the protective nature of identifying with groups that possess healthy norms. They also offer further evidence to support the distinction between group identification and group contact, in terms of the differing impact that these two variables may have on health behaviours. We believe that these findings could have potentially important implications for parents, teachers, social workers, child psychiatrists, and numerous other stakeholders looking for ways to improve young people's wellbeing. 


\section{References}

Ấstrøm, A. N., \& Rise, J. (2001). Young adults’ intention to eat healthy food: Extending the theory of planned behaviour. Psychology and Health, 16, 223-237. doi:10.1080/08870440108405501.

Beckwith, M., Best, D., Dingle, G. A, Perryman, C., \& Lubman, D. (2015) Predictors of flexibility in social identity among people entering a therapeutic community for substance abuse. Alcoholism Treatment Quarterly, 33:1, 93-104. doi: 10.1080/07347324.2015.982465.

Best, D., Beckwith, M., Haslam, C., Haslam, S.A., Jetten, J., Mawson, E., \& Lubman, D. I. (2016). Overcoming drug and alcohol addiction as a process of social identity transition: The Social Identity Model of Recovery (SIMOR). Addiction, Research and Theory. 24, 111-123, doi: 10.3109/16066359.2015.1075980.

Bizumic, B., Reynolds, K. J., Turner, J. C., Bromhead, D., \& Subasic, E., 2009. The role of the group in individual functioning: school identification and the psychological well-being of staff and students. Applied Psychology 58, 171-192. http://dx.doi.org/ 10.1111/j.1464-0597.2008.00387.x.

Brener, N. D. et al (2004). Methodology of the youth risk behaviour surveillance system. MMWR Recommendations and Reports. 53, 1-13.

Cruwys, T., Haslam, S. A., Dingle, G. A., Jetten, J., Hornsey, M. J., Chong, E. M. D., \& Oei, T. P. S. (2014). Feeling connected again: Interventions that increase social identification reduce depression symptoms in community and clinical settings. Journal of Affective Disorders, 159, 139146. http://dx.doi.org/10.1016/j.jad.2014.02.019.

Cruwys, T., Haslam, S. A., Fox, N. E. \& McMahon, H. (2015). “That's not what we do": Evidence that normative change is a mechanism of action in group interventions. Behaviour Research and Therapy, 65, 11-17. doi:10.1016/j.brat.2014.12.003. 
Cruwys, T., Dingle, G.A., Haslam, C., Haslam, S.A., Jetten, J., \& Morton, T.A., (2013). Social group memberships protect against future depression, alleviate depression symptoms and prevent depression relapse. Social Science and Medicine 98, 179-186. doi: 10.1016/j.socscimed.2013.09.013.

Dingle, G. A., Cruwys, T., \& Frings, D. (2015). Social identities as pathways into and out of addiction. Frontiers in Psychology, 30 (6), 1795. doi: 10.3389/fpsyg.2015.01795.

Dingle, G. A., Stark, C., Cruwys, T., \& Best, D. (2014). Breaking good: Breaking ties with social groups may be good for recovery from substance misuse. British Journal of Social Psychology, 54, 236-254. doi: 10.1111/bjso.12081.

Doosje, B., Ellemers, N., \& Spears, R. (1995). Perceived intragroup variability as a function of group status and identification. Journal of Experimental Social Psychology, 31, 410-436. doi: 10.1006/jesp.1995.1018.

Frings, D., \& Albery, P. (2015). The Social Identity Model of Cessation Maintenance: Formulation and initial evidence. Addictive Behaviours, 44, 35-75. doi: 10.1016/j.addbeh.2014.10.023.

Haslam, S. A. (2004). Psychology in organizations: The social identity approach. London: Sage.

Haslam, S. A., Jetten, J., Postmes, T., \& Haslam, C. (2009). Social identity, health and wellbeing: An emerging agenda for applied psychology. Applied Psychology, 58, 1-23. doi: 10.1111/j.1464-0597.2008.00379.x.

Hogg, M. A., Siegel, J. T., \& Hohman, Z. P. (2011). Groups can jeopardize your health: Identifying with unhealthy groups to reduce self-uncertainty. Self and Identity, 10 (3), 326-335. doi: $10.1080 / 15298868.2011 .558762$. 
Jetten, J., Haslam, C., \& Haslam, S. A. (2012). The social cure: Identity, health and wellbeing. New York: Psychology Press.

Kelder, S. H., Perry, C. L., Kelpp, K. I., \& Lytle, L. L. (1994). Longitudinal tracking of adolescent smoking, physical activity, and food choice behaviors. American Journal of Public Health, 84, 1121-1126. Doi:10.2105/AJPH.84.7.1121.

Khan, S. S., Hopkins, N., Tewari, S., Srinivasan, N., Reicher, S. D., \& Ozakinci, G. (2014). Efficacy and well-being in rural north India: The role of social identification with a large-scale community identity. European Journal of Social Psychology, 44 (7), 787-798. doi: 10.1002/ejsp.2060.

Livingstone, A. G., Young, H., \& Manstead, A. S. R. (2011). "We drink, therefore we are": The role of group identification and norms in sustaining and challenging heavy drinking "culture". Group Processes \& Intergroup Relations, 14, 637-649. doi: 10.1177/1368430210392399.

Miller, K., Wakefield, J. R. H., \& Sani, F. (2015). Identification with social groups is associated with mental health in adolescents: Evidence from a Scottish community sample. Psychiatry Research, 228, 340-346. doi: 10.1016/j.psychres.2015.05.088.

Rivis, A., \& Sheeran, P. (2003). Social influences and the theory of planned behaviour: Evidence for a direct relationship between prototypes and young people's exercise behaviour. Psychology and Health, 18 (5), 567-583. doi: 10.1080/0887044032000069883.

Sani, F., Herrera, M., Wakefield, J. R. H., Boroch, O., \& Gulyas, C. (2012). Comparing social contact and group identification as predictors of mental health. British Journal of Social Psychology, 51, 781-790. doi: 10.1111/j.2044-8309.2012.02101.x. 
Sani, F., Madhok, V., Norbury, M., Dugard, P., Wakefield, J. R. H. (2015). Higher identification with social groups is associated with healthier behavior: Evidence from a Scottish community sample. British Journal of Health Psychology. doi: 10.1111/bjhp.12119.

Schofield, P. E., Pattison, P. E., Hill, D. J., \& Borland, R. (2001). Youth culture and smoking: Integrating social group processes and individual cognitive processes in a model of health-related behaviours. Journal of Health Psychology, 8, 291-306. doi: 10.1177/13591053030083001.

Tajfel, H., \& Turner, J. C. (1986). The social identity theory of intergroup behaviour. In S. Worchel and W. G. Austin (1986), Psychology of intergroup relations (pp. 2-24). Chicago: NelsonHall Publishers.

Terry, D. J., \& Hogg, M. A. (1996). Group norms and the attitude-behaviour relationships: A role for group identification. Personality and Social Psychology Bulletin, 22, 775-793. doi: $10.1177 / 0146167296228002$.

Tomasello, M. (2014). The ultra-social animal. European Journal of Social Psychology, 44, 187-194. doi: 10.1002/ejsp.2015.

Turner, J. C., Hogg, M. A., Oakes, P., Reicher, S., \& Wetherell, M. (1987). Rediscovering the social group: A self-categorization theory. Oxford: Basil-Blackwell.

Verkooijen, K. T., de Vries, N. K. \& Nielsen, G. A. (2007). Youth crowds and substance use: The impact of perceived group norm and multiple group identification. Psychology of Addictive Behaviours, 21 (1), 55-61. doi: http://dx.doi.org/10.1037/0893-164X.21.1.55.

Viner, R.M., Ozer, E. M., Denny, S., Marmot, M., Resnick, M., Fatusi, A. \& Currie, C. (2012). Adolescence and the social determinants of health. Lancet, 379 (9826). 1641-1652. doi: http://dx.doi.org/10.1016/S0140-6736(12)60149-4. 
Wakefield, J. R. H., Bickley, S. \& Sani, F. (2013). The effects of identification with a support group on the mental health of people with multiple sclerosis. Journal of Psychosomatic Research, 74, 420-426. doi: 10.1016/j.jpsychores.2013.02.002.

Wegge, J., Van Dick, R., Fisher, G.K., Wecking, C., Moltzen, K., 2006. Work motivation, organisational identification, and well-being in call centre work. Work Stress 20, 60-83. http://dx.doi.org/10.1080/02678370600655553. 
Table 1. Frequencies and percentages for the health behaviour variables at each level of Strong Group Identifications (0-3), including chi-square values

\begin{tabular}{|c|c|c|c|c|c|c|}
\hline \multirow{2}{*}{$\begin{array}{l}\text { No. of Strong } \\
\text { Identifications }\end{array}$} & \multicolumn{2}{|c|}{ Smoking } & \multicolumn{2}{|c|}{ Binge Drinking } & \multicolumn{2}{|c|}{ Cannabis Use } \\
\hline & No & Yes & No & Yes & No & Yes \\
\hline 0 & 60 & 19 & 45 & 32 & 67 & 10 \\
\hline$(n=80)$ & $75.9 \%$ & $24.1 \%$ & $58.4 \%$ & $41.6 \%$ & $87.0 \%$ & $13.0 \%$ \\
\hline 1 & 109 & 39 & 81 & 67 & 123 & 25 \\
\hline$(n=151)$ & $73.6 \%$ & $26.4 \%$ & $54.7 \%$ & $45.3 \%$ & $83.1 \%$ & $16.9 \%$ \\
\hline 2 & 285 & 53 & 222 & 116 & 304 & 33 \\
\hline$(n=344)$ & $84.3 \%$ & $15.7 \%$ & $65.7 \%$ & $34.3 \%$ & $90.2 \%$ & $9.8 \%$ \\
\hline 3 & 478 & 46 & 389 & 134 & 747 & 57 \\
\hline \multirow[t]{2}{*}{$(n=527)$} & $91.2 \%$ & $8.8 \%$ & $74.4 \%$ & $25.6 \%$ & $97.3 \%$ & $2.7 \%$ \\
\hline & \multicolumn{2}{|c|}{$\chi^{2}(3)=36.97 ; p<.001$} & \multicolumn{2}{|c|}{$\chi^{2}(3)=25.76 ; p<.001$} & \multicolumn{2}{|c|}{$\chi^{2}(3)=41.95 ; p<.001$} \\
\hline
\end{tabular}

Note. 9 participants had a missing value for No. of Strong Identifications-they are excluded from this table. Missing values prevent frequencies in the table always summing to match the overall $N \mathrm{~s}$ in the first column, and also prevent the percentage frequencies of two levels of the same binary variable always totalling to $100 \%$. 
Table 2. Frequencies and percentages for the health behaviour variables at each level of Contact-Intensive Groups (0-3), including chi-square values

\begin{tabular}{|c|c|c|c|c|c|c|}
\hline \multirow{3}{*}{$\begin{array}{l}\text { No. of Contact- } \\
\text { Intensive Groups }\end{array}$} & \multicolumn{2}{|c|}{ Smoking } & \multicolumn{2}{|c|}{ Binge Drinking } & \multicolumn{2}{|c|}{ Cannabis Use } \\
\hline & \multirow[t]{2}{*}{ No } & \multirow[t]{2}{*}{ Yes } & \multirow[t]{2}{*}{ No } & \multirow[t]{2}{*}{ Yes } & \multirow[t]{2}{*}{ No } & \multirow[t]{2}{*}{ Yes } \\
\hline & & & & & & \\
\hline 0 & 373 & 55 & 304 & 122 & 400 & 26 \\
\hline$(n=433)$ & $87.1 \%$ & $12.9 \%$ & $71.4 \%$ & $28.6 \%$ & $93.9 \%$ & $6.1 \%$ \\
\hline 1 & 276 & 39 & 220 & 94 & 291 & 23 \\
\hline$(n=317)$ & $87.6 \%$ & $12.4 \%$ & $70.1 \%$ & $29.9 \%$ & $92.7 \%$ & $7.3 \%$ \\
\hline 2 & 129 & 24 & 91 & 62 & 139 & 14 \\
\hline$(n=155)$ & $84.3 \%$ & $15.7 \%$ & $59.5 \%$ & $40.5 \%$ & $90.8 \%$ & $9.2 \%$ \\
\hline 3 & 38 & 9 & 27 & 20 & 42 & 5 \\
\hline \multirow[t]{2}{*}{$(n=48)$} & $80.9 \%$ & $19.1 \%$ & $57.4 \%$ & $42.6 \%$ & $89.4 \%$ & $10.6 \%$ \\
\hline & \multicolumn{2}{|c|}{$\chi^{2}(3)=2.41 ; n s$} & \multicolumn{2}{|c|}{$\chi^{2}(3)=10.35 ; p=.02$} & \multicolumn{2}{|c|}{$\chi^{2}(3)=2.46 ; n s$} \\
\hline
\end{tabular}

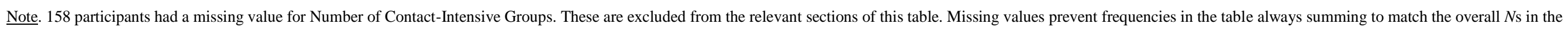
first column, and also prevent the percentage frequencies of two levels of the same binary variable always totalling to $100 \%$. 
Table 3. Frequencies and percentages for health behaviour and gender, including chi-square values

\begin{tabular}{|c|c|c|c|c|c|c|}
\hline \multirow[b]{2}{*}{ Gender } & \multicolumn{2}{|c|}{ Smoking } & \multicolumn{2}{|c|}{ Binge Drinking } & \multicolumn{2}{|c|}{ Cannabis Use } \\
\hline & No & Yes & No & Yes & No & Yes \\
\hline Female & 451 & 98 & 355 & 192 & 510 & 34 \\
\hline$(n=553)$ & $82.1 \%$ & $17.9 \%$ & $64.9 \%$ & $35.1 \%$ & $93.8 \%$ & $6.3 \%$ \\
\hline Male & 486 & 58 & 385 & 158 & 496 & 48 \\
\hline \multirow[t]{2}{*}{$(n=553)$} & $89.3 \%$ & $10.7 \%$ & $70.9 \%$ & $29.1 \%$ & $91.2 \%$ & $8.8 \%$ \\
\hline & \multicolumn{2}{|c|}{$\chi^{2}(1)=11.54 ; p<.001$} & \multicolumn{2}{|c|}{$\chi^{2}(1)=4.5 ; p=.03$} & \multicolumn{2}{|c|}{$\chi^{2}(1)=2.59 ; n s$} \\
\hline
\end{tabular}

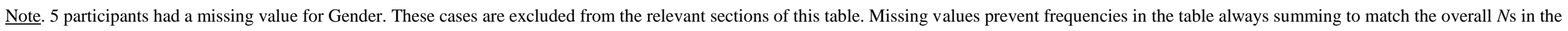
first column, and also prevent the percentage frequencies of two levels of the same binary variable always totalling to $100 \%$. 
Table 4. Summary of logistic regression analysis for variables predicting Smoking

\begin{tabular}{|c|c|c|c|c|c|c|c|}
\hline \multirow[t]{2}{*}{ Variable } & \multirow[t]{2}{*}{ B } & \multirow[t]{2}{*}{ SE } & \multirow{2}{*}{$\begin{array}{l}\text { Wald } \\
\text { statistic }\end{array}$} & \multirow[t]{2}{*}{$p$} & \multirow[t]{2}{*}{ Odds ratio } & \multicolumn{2}{|c|}{$95 \%$ CI for Odds Ratio } \\
\hline & & & & & & Lower & Upper \\
\hline No. of Strong Group & -.48 & .10 & $23.72 * * *$ & $<.001$ & .62 & .51 & .75 \\
\hline \multicolumn{8}{|l|}{ Identifications } \\
\hline No of Contact-Intensive & .27 & .11 & $5.89 * *$ & .01 & 1.31 & 1.05 & 1.62 \\
\hline \multicolumn{8}{|l|}{ Groups } \\
\hline Gender & -.66 & .21 & $10.19 * *$ & .004 & .52 & .35 & .78 \\
\hline Age & .22 & .10 & $4.50 *$ & .03 & 1.24 & 1.02 & 1.52 \\
\hline
\end{tabular}

$* p<.05 ; * * p<.01 ; * * * p<.001$. 
Table 5. Summary of logistic regression analysis for variables predicting Binge Drinking

$\begin{array}{lllll}\text { Variable } & \text { B } & \text { SE } & \text { Wald statistic } & p\end{array}$ Odds ratio $95 \%$ CI for Odds Ratio

Lower Upper

$\begin{array}{llllllll}\text { No. of Strong Group } & -.34 & .08 & 17.35^{* * *} & <.001 & .72 & .61 & .84\end{array}$

Identifications

\begin{tabular}{lccccccc} 
No. of Contact- & .37 & .09 & $18.77^{* * *}$ & $<.001$ & 1.45 & 1.23 & 1.71 \\
Intensive Groups & & & & & & \\
& & & & & & \\
\\
Gender & -.38 & .15 & $6.18^{*}$ & .01 & .68 & .51 & .92 \\
& & & & & & & \\
Age & .71 & .08 & $72.41^{* * *}$ & $<.001$ & 2.03 & 1.73 & 2.39 \\
\hline
\end{tabular}

$* p<.05 ; * * p<.01 ; * * * p<.001$. 
Running head: IDENTIFICATION AND HEALTH BEHAVIOUR IN ADOLESCENTS

Table 6. Summary of logistic regression analysis for variables predicting Cannabis Use

\begin{tabular}{|c|c|c|c|c|c|c|c|}
\hline \multirow[t]{2}{*}{ Variable } & \multirow[t]{2}{*}{ B } & \multirow[t]{2}{*}{ SE } & \multirow{2}{*}{$\begin{array}{l}\text { Wald } \\
\text { statistic }\end{array}$} & \multirow[t]{2}{*}{$p$} & \multirow[t]{2}{*}{ Odds ratio } & \multicolumn{2}{|c|}{$95 \%$ CI for Odds Ratio } \\
\hline & & & & & & Lower & Upper \\
\hline Number of Strong & -.66 & .13 & $26.79 * * *$ & $<.001$ & .52 & .41 & .67 \\
\hline \multicolumn{8}{|l|}{ Group Identifications } \\
\hline Number of Contact- & .36 & .14 & $6.32 *$ & .01 & 1.43 & 1.08 & 1.88 \\
\hline \multicolumn{8}{|l|}{ Intensive Groups } \\
\hline Gender & .34 & .26 & 1.66 & .20 & 1.40 & .84 & 2.34 \\
\hline Age & .22 & .13 & 2.72 & .10 & 1.24 & .96 & 1.61 \\
\hline
\end{tabular}

$* p<.05 ; * * p<.01 ; * * * p<.001$ 
Table 7: Summary of logistic regression analysis for groups predicting smoking

\begin{tabular}{|c|c|c|c|c|c|c|c|}
\hline \multirow[t]{2}{*}{ Variable } & \multirow[t]{2}{*}{ B } & \multirow[t]{2}{*}{$\mathrm{SE}$} & \multirow{2}{*}{$\begin{array}{c}\text { Wald } \\
\text { statistic }\end{array}$} & \multirow[t]{2}{*}{$p$} & \multirow[t]{2}{*}{ Odds ratio } & \multicolumn{2}{|c|}{$95 \%$ CI for Odds Ratio } \\
\hline & & & & & & Lower & Upper \\
\hline Family Identification & -.43 & .09 & $22.6^{* * *}$ & $<.001$ & .65 & .54 & .78 \\
\hline School Identification & -.29 & .1 & $8.89 * *$ & 0.003 & .75 & .62 & .91 \\
\hline Friend Identification & .3 & .13 & $5.29 *$ & .02 & 1.35 & 1.05 & 1.75 \\
\hline Family Contact & .09 & .09 & 1.14 & .29 & 1.1 & .93 & 1.3 \\
\hline School Contact & .16 & .08 & 3.66 & .06 & 1.17 & .1 & 1.38 \\
\hline Friend Contact & .08 & .08 & .91 & .34 & 1.08 & .92 & 1.27 \\
\hline Gender & -.72 & .21 & $11.33 * *$ & .001 & .49 & .32 & 0.74 \\
\hline Age & .24 & .11 & $5.4^{*}$ & .02 & 1.28 & 1.04 & 1.57 \\
\hline
\end{tabular}


Table 8: Summary of logistic regression analysis for groups predicting binge drinking

\begin{tabular}{|c|c|c|c|c|c|c|c|}
\hline \multirow[t]{2}{*}{ Variable } & \multirow[t]{2}{*}{ B } & \multirow[t]{2}{*}{ SE } & \multirow{2}{*}{$\begin{array}{c}\text { Wald } \\
\text { statistic }\end{array}$} & \multirow[t]{2}{*}{$p$} & \multirow[t]{2}{*}{ Odds ratio } & \multicolumn{2}{|c|}{$95 \%$ CI for Odds Ratio } \\
\hline & & & & & & Lower & Upper \\
\hline Family Identification & -.37 & .09 & $18.75^{* * *}$ & $<.001$ & .69 & .58 & .82 \\
\hline School Identification & -.31 & .08 & $14.39 * * *$ & $<.001$ & .73 & .62 & .86 \\
\hline Friend Identification & .49 & .12 & $17.37 * * *$ & $<.001$ & 1.63 & 1.29 & 2.04 \\
\hline Family Contact & .03 & .08 & .15 & .7 & 1.03 & .89 & 1.2 \\
\hline School Contact & .36 & .12 & $8.98 * *$ & .003 & 1.43 & 1.13 & 1.81 \\
\hline Friend Contact & .1 & .15 & .44 & .51 & 1.1 & .83 & 1.47 \\
\hline Gender & -.4 & .16 & $6.4^{*}$ & .01 & .67 & .5 & 0.92 \\
\hline Age & .74 & .09 & $74.74 * * *$ & $<.001$ & 2.1 & 1.78 & 2.49 \\
\hline
\end{tabular}

$* p<.05 ; * * p<.01 ; * * * p<.001$ 
Table 9: Summary of logistic regression analysis for groups predicting cannabis use

\begin{tabular}{|c|c|c|c|c|c|c|c|}
\hline \multirow[t]{2}{*}{ Variable } & \multirow[t]{2}{*}{ B } & \multirow[t]{2}{*}{ SE } & \multirow{2}{*}{$\begin{array}{c}\text { Wald } \\
\text { statistic }\end{array}$} & \multirow[t]{2}{*}{$p$} & \multirow[t]{2}{*}{ Odds ratio } & \multicolumn{2}{|c|}{$95 \%$ CI for Odds Ratio } \\
\hline & & & & & & Lower & Upper \\
\hline Family Identification & -.45 & .11 & $17.15 * * *$ & $<.001$ & .64 & .52 & .79 \\
\hline School Identification & -.47 & .12 & $16.35 * * *$ & $<.001$ & .63 & .5 & .79 \\
\hline Friend Identification & .38 & .17 & $5.35^{*}$ & .02 & 1.47 & 1.06 & 2.03 \\
\hline Family Contact & .14 & .1 & 2.21 & .14 & 1.16 & .96 & 1.4 \\
\hline School Contact & .08 & .09 & .68 & .41 & 1.08 & .9 & 1.29 \\
\hline Friend Contact & .12 & .21 & .33 & .57 & 1.13 & .75 & 1.71 \\
\hline Gender & .26 & .27 & .94 & .33 & 1.3 & .77 & 2.21 \\
\hline Age & .26 & .14 & 3.53 & .06 & 1.3 & .99 & 1.7 \\
\hline
\end{tabular}

\footnotetext{
$* p<.05 ; * * p<.01 ; * * * p<.001$.
} 